\title{
Novel Biological Hydrogel: Swelling Behaviors Study in Salt Solutions with Different Ionic Valence Number
}

\author{
Yu Wang ${ }^{1, *}(\mathbb{D})$, Guidong $\mathrm{He}^{2}$, Zheng $\mathrm{Li}^{2,3, *}$, Jiachuan Hua ${ }^{2}$, Maoqi Wu ${ }^{2}$, Jixian Gong ${ }^{2}$, \\ Jianfei Zhang ${ }^{2}$, Li-tong Ban ${ }^{1}$ and Liang Huang ${ }^{1}$ \\ 1 College of Agronomy and Resources Environment, Tianjin Agricultural University, Tianjin 300384, China; \\ banlitong@126.com (L.t.B.); huangliang@tjau.edu.cn (L.H.) \\ 2 Key Laboratory of Advanced Textile Composites (Tianjin Polytechnic University), Ministry of Education; \\ School of Textiles, Tianjin Polytechnic University, Tianjin 300387, China; calvinheguidong@163.com (G.D.); \\ huajiachuan@sina.com (J.H.); wwumaoqi@163.com (M.W.); gongjixian@163.com (J.G.); \\ zhangjianfei1960@126.com (J.Z.) \\ 3 Key Laboratory of Science \& Technology of Eco-Textile, Donghua University, Shanghai 201620, China \\ * Correspondence: wytjac@163.com (Y.W.); lizheng_nx@163.com (Z.L.); Tel.: +86-22-6091-2562 (Y.W.)
}

Received: 18 December 2017; Accepted: 22 January 2018; Published: 24 January 2018

\begin{abstract}
In this paper, poly $\gamma$-glutamic acid $/ \varepsilon$-polylysine $(\gamma$-PGA $/ \varepsilon$-PL) hydrogels were successful prepared. The $\gamma$-PGA/ $\varepsilon$-PL hydrogels could be used to remove $\mathrm{Na}^{+}, \mathrm{Ca}^{2+}$, and $\mathrm{Cr}^{3+}$ from aqueous solution and were characterized by scanning electron microscopy. The performance of hydrogels were estimated under different ionic concentration, temperature, and $\mathrm{pH}$. The results showed that the ionic concentration and the $\mathrm{pH}$ significantly influenced the swelling capacity of $\gamma$-PGA $/ \varepsilon-\mathrm{PL}$ hydrogels. The swelling capacities of $\gamma$-PGA $/ \varepsilon$-PL hydrogels were decreased with the increase of the ionic concentration. However, the swelling capacity of the $\gamma$-PGA $/ \varepsilon-$ PL hydrogel was increased with the increase of the $\mathrm{pH}$. The swelling kinetics indicated that $\gamma-\mathrm{PGA} / \varepsilon$-PL hydrogels presented a more limited swelling degree in metal ion solutions with higher ionic valence numbers than in ion solutions with lower ionic valence numbers. However, the swelling kinetics of $\gamma$-PGA $/ \varepsilon$-PL hydrogels showed that they proposed a satisfactory description in $\mathrm{NaCl}$ and $\mathrm{CaCl}_{2}$ solutions. The adsorption process was fitted with a pseudo-second-order rate equation model. Moreover, the desorption kinetics of $\gamma$-PGA $/ \varepsilon$-PL hydrogels showed that they could release most of the adsorption ions. Considering the biocompatibility, biodegradability, and ionic-sensitive properties, we propose that these $\gamma$-PGA/ $\varepsilon$-PL hydrogels have high potential to be used in environmental protection, medical treatment, and other related fields.
\end{abstract}

Keywords: poly $\gamma$-glutamic acid; $\varepsilon$-polylysine; hydrogels; swelling behaviors

\section{Introduction}

During the past decades, hydrogels, as a kind novel functional material, have been the material of choice for many applications due to their unique biocompatibility, flexible methods of synthesis, desirable physical characteristics, adjustable biomimetic properties, and absorbing ability $[1,2]$. They can serve in tissue engineering [3,4], wound-dressing [5,6], drug delivery systems $[7,8]$, superabsorbents $[9,10]$ and many other related branches of study. Natural polymers and synthetic polymers could be used to prepare hydrogels [11]. However, more and more novel hydrogels with biodegradability and stimulus responsive have been prepared from natural polymers in recent years [12-14].

Our society has suffered a great deal from industrial ion wastewater pollution. Ion wastewater is one of the most serious environment problem, globally. Even in very low concentration, metal ions, such as $\mathrm{Cu}^{2+}, \mathrm{Cr}^{3+}$, and $\mathrm{Cd}^{2+}$, can accumulate in the environment and/or living tissues, generating 
various diseases and abnormalities in living organisms [15-18]. Thus, removal of metal ions from the aquatic environment is a vital issue. Many researchers have focused on the production of effective methods for removing metal ions from wastewater, including chemical precipitation, ion-exchange, electrochemical treatment, membrane separation, and others [19]. However, these techniques have some disadvantages, such as inefficiency, high-cost, the formation of toxic sludge, and other waste products [20]. Hence, developing cheaper, efficient, and environmentally-friendly adsorbents and technologies are attracting the attention of researchers [21]. Hydrogels, as a kind of unique adsorbent, have the potential for effective ion removal and have receive increasing attention compared with conventional counterparts [22].

Hydrogels, which are defined as a three-dimensional polymer network composed of cross-linked hydrophilic polymer chains and hold a significant amount of aqueous solvent [11]. As a new type of adsorbent, hydrogels can be practically made into any shape or size [23,24]. Hydrogel can absorb liquids to reach 1000-fold of their dry weight because of the hydrophilic groups of the network and retain important fractions of water within its structure, but they do not dissolve [25]. Among natural polymers, poly $\gamma$-glutamic acid ( $\gamma$-PGA) has gained significant attention to the preparation of hydrogels. $\gamma$-PGA is a non-poisonous, esculent, and anionic polypeptide biomaterial [26]. Now, it can be mass produced by microbial fermentation [27]. Similarly, natural $\varepsilon$-polylysine ( $\varepsilon$-PL) is also biodegradable, esculent, and non-poisonous towards humans, and is environmentally-friendly $[14,28]$. $\varepsilon-\mathrm{PL}$ is a cationic polyamide biomaterial that is composed of $\varepsilon-\mathrm{NH}_{2}-\alpha-\mathrm{COOH}$ with an L-lysine linkage and has antibacterial properties $[29,30]$.

In this study, we prepared a type of novel $\gamma$-PGA/ $\varepsilon$-PL hydrogel by EDC/NHS mediated polymerization. We studied the effects of $\mathrm{pH}$, temperature, ion concentration, and ion valence number on the swelling characteristics of $\gamma$-PGA/ $/ \varepsilon$-PL hydrogels. The pseudo-first-order and pseudo-second-order equations were utilized to verify the mechanism and kinetics of the swelling process. At the same time, the desorption kinetics of $\gamma$-PGA $/ \varepsilon$-PL hydrogels was also investigated.

\section{Materials and Methods}

\subsection{Materials}

Poly $\gamma$-glutamic acid was provided from Shineking Biotechnology (Nanjing, China). $\varepsilon$-Polylysine was offered from Silver-Elephant Bio-engineering Co. (Zhejiang, China). 4-Morpholineethanesulfonic acid (MES), N-hydroxysuccinimide (NHS), and 1-ethyl-3-(3-dimethylaminopropyl) carbodiimide hydrochloride (EDC $\cdot \mathrm{HCl}$ ) were supplied from Sinopharm Chemical Reagent Co. (Shanghai, China), respectively. $\mathrm{NaCl}, \mathrm{CaCl}_{2}$, and $\mathrm{CrCl}_{3} \cdot 6 \mathrm{H}_{2} \mathrm{O}$ were purchased from Sinopharm group Co., Ltd. (Shanghai, China).

\subsection{Preparation of $\gamma-P G A / \varepsilon-P L$ Hydrogels}

$\gamma$-PGA / $\varepsilon$-PL hydrogels were prepared by the EDC/NHS mediated system and the molar ratio of $\gamma$-PGA: $\varepsilon$-PL:EDC:NHS was 1:0.1:0.25:0.25 [14]. Firstly, $0.1 \mathrm{~mol} / \mathrm{L}$ MES solution were prepared by deionized water. Then, $\gamma$-PGA and $\varepsilon$-PL were dissolved into pre-made $0.1 \mathrm{~mol} / \mathrm{L}$ MES solution, respectively. After that, the $\gamma$-PGA $/ \varepsilon$-PL solution was obtained by slowly adding $\varepsilon$-PL solution into $\gamma$-PGA solution and stirring at $100 \mathrm{r} / \mathrm{min}$ for $15 \mathrm{~min}$, shifting it into a $0{ }^{\circ} \mathrm{C}$ refrigerator for $40 \mathrm{~min}$. Afterward, the NHS was dissolved into the $\gamma$-PGA $/ \varepsilon$-PL solution and EDC was added in order. Finally, the $\gamma$-PGA $/ \varepsilon$-PL hydrogel could be quickly made after stirring at $100 \mathrm{r} / \mathrm{min}$ for $10 \mathrm{~min}$ [14].

\subsection{Swelling Study}

The swelling study was conducted in three different concentrations of $\mathrm{Na}^{+}, \mathrm{Ca}^{2+}$, and $\mathrm{Cr}^{3+}$ solutions (as shown in Figure 1). $\gamma$-PGA $/ \varepsilon$-PL hydrogel cubes were dried in a drying oven at $50{ }^{\circ} \mathrm{C}$. Then, dried hydrogels were dipped into $200 \mathrm{~mL} \mathrm{Na}^{+}, \mathrm{Ca}^{2+}$, and $\mathrm{Cr}^{3+}$ solution, respectively, to equilibrium at room temperature. The weights of the wet hydrogels $\left(W_{0}\right)$ were evaluated at $24 \mathrm{~h}$. 
The wet hydrogels were then completely dried at $50{ }^{\circ} \mathrm{C}$ and the weights of dry hydrogels $\left(W_{\mathrm{d}}\right)$ were evaluated $[31,32]$. The swelling degree $(Q)$ is expressed by Equation (1):

$$
Q=\left(W_{0}-W_{\mathrm{d}}\right) / W_{\mathrm{d}}
$$

. ions
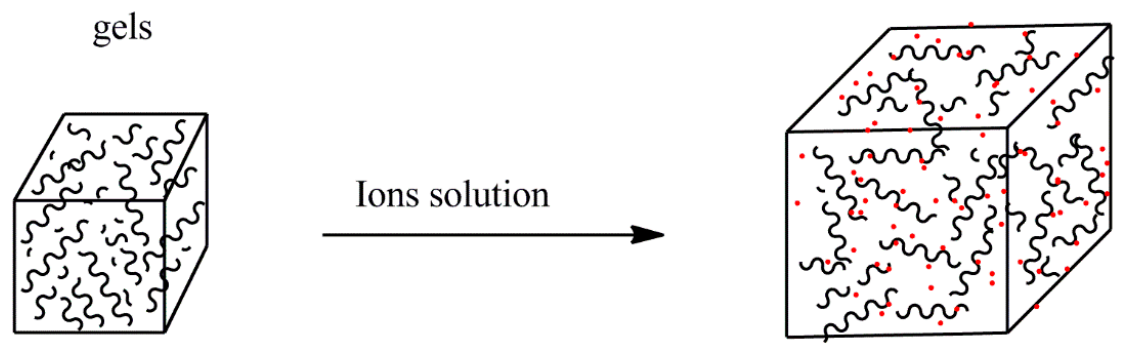

Figure 1. The simulation of the swelling of $\gamma$-PGA/ $\varepsilon$-PL hydrogels in ion solutions.

\subsubsection{The Effects of $\mathrm{pH}$ and Temperature}

The effect of $\mathrm{pH}$ on swelling characteristics was studied by adding the dried hydrogels into $200 \mathrm{~mL} 0.0154 \mathrm{~mol} / \mathrm{L}$ ion solutions. The ions solutions were adjusted on the $\mathrm{pH}$ values $(\mathrm{pH} 1-7.0$ for $\mathrm{Na}^{+}$and $\mathrm{Ca}^{2+}, 1-5.0$ for $\mathrm{Cr}^{3+}$ ) by hydrochloric acid and/or sodium hydroxide. The solutions were placed at room temperature for $24 \mathrm{~h}$. To study the effect of temperature on swelling characteristics, the dried hydrogels were added into $200 \mathrm{~mL} 0.0154 \mathrm{~mol} / \mathrm{L}$ ion solutions and in an incubator at 15, 30, 45 , and $60^{\circ} \mathrm{C}$ for $24 \mathrm{~h}$.

\subsubsection{The Swelling Kinetic Study}

The swelling kinetic was tested at different concentrations of $\mathrm{Na}^{+}, \mathrm{Ca}^{2+}$, and $\mathrm{Cr}^{3+}$ solutions. $\gamma$-PGA $/ \varepsilon$-PL hydrogels were dried at $50{ }^{\circ} \mathrm{C}$. The dried hydrogels were dipped into $200 \mathrm{~mL} \mathrm{Na}^{+}$, $\mathrm{Ca}^{2+}$, and $\mathrm{Cr}^{3+}$ solutions to equilibrium at room temperature. The swelling rate in salt solution of $\gamma$-PGA $/ \varepsilon$-PL hydrogels could be calculated by pseudo-first-order and pseudo-second-order kinetics models. The two models were expressed from the following Equations (2) and (3), respectively [33,34]:

$$
\begin{gathered}
\lg \left(Q_{\mathrm{e}}-Q_{\mathrm{t}}\right)=\lg Q_{\mathrm{e}}-\frac{K_{1} t}{2.303} \\
\frac{t}{Q_{\mathrm{t}}}=\frac{1}{K_{2} Q_{\mathrm{e}}^{2}}+\frac{t}{Q_{\mathrm{e}}}
\end{gathered}
$$

where $Q_{\mathrm{t}}(\mathrm{g} / \mathrm{g})$ and $Q_{\mathrm{e}}(\mathrm{g} / \mathrm{g})$ are the amount of swelling in equilibrium and at time $t ; K_{1}\left(\mathrm{~min}^{-1}\right)$ and $K_{2}\left(\mathrm{~min}^{-1}\right)$ are the rate constant of the pseudo-first-order and pseudo-second-order kinetics models, respectively.

\subsection{The Desorption Kinetic}

The desorption kinetics were carried out in deionized water at room temperature (as shown in Figure 2). In order to prepare ion loaded hydrogels, the hydrogels were immersed in $100 \mathrm{~mL}$ $0.0154 \mathrm{~mol} / \mathrm{L}$ ion solutions for $24 \mathrm{~h}$ until equilibrium. Then, the ion-loaded gels were taken out and dried in a drying oven until constant weight. Dry gels were soaked in deionized water $(50 \mathrm{~mL})$ at room temperature. The conductivity was recorded by a conductivity meter. Then, the conductivity was transformed into the ion concentration by using the standard curve obtained with a series of standard ion solutions [35]. 

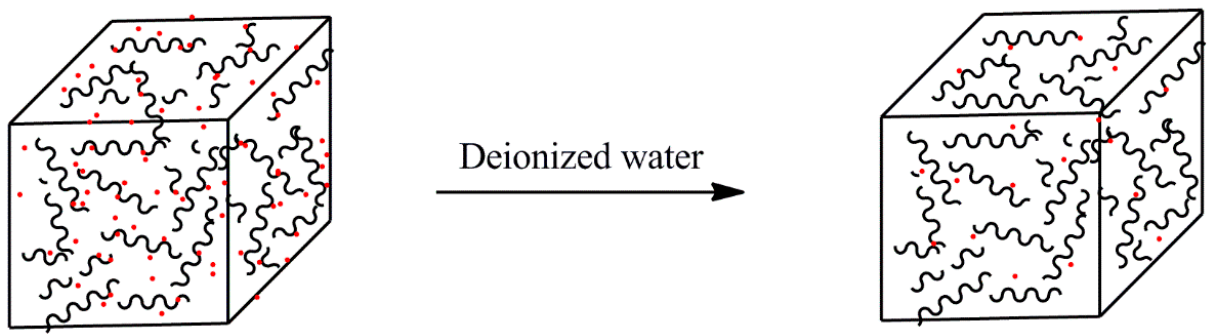

Figure 2. The simulation of desorption of $\gamma$-PGA $/ \varepsilon$-PL hydrogels in deionized water.

\section{Results and Discussion}

\subsection{Preparation of Hydrogels}

$\gamma$-PGA/ $\varepsilon$-PL hydrogels were prepared by the EDC/NHS mediated system. As shown in Table 1, after swelling equilibrium, $\gamma$-PGA $/ \varepsilon-\mathrm{PL}$ hydrogels displayed a similar color as those of the ion solutions. This indicated that swelled hydrogels adsorbed metal ions into their structure. Then, the cross-section and surface morphology of $\gamma$-PGA $/ \varepsilon-P L$ hydrogels were visualized by SEM (TM-3030, Hitachi, Japan). $\gamma$-PGA/ $\varepsilon$-PL hydrogels showed a three dimensional network and the porous structure of hydrogels was covered with irregularly-shaped holes [14]. With the ionic valence number increased, the network structures became smaller and presented a slight collapse. While swelled in $\mathrm{CrCl}_{3}$ solution, the porous structure in the hydrogels almost completely collapsed. These phenomena indicated that increasing the ionic valence number could hinder the swelling behavior of $\gamma$-PGA $/ \varepsilon$-PL hydrogels.

Table 1. The morphology of $\gamma$-PGA/ $\varepsilon$-PL hydrogels after swelling equilibrium in $0.1540 \mathrm{~mol} / \mathrm{L} \mathrm{NaCl}$,

$\mathrm{CaCl}_{2}$, and $\mathrm{CrCl}_{3}$ solutions.

Form




\subsection{Swelling Study}

\subsubsection{The Effects of $\mathrm{pH}$ and Temperature}

The effect of $\mathrm{pH}$ on the swelling behavior of $\gamma$-PGA/ $\varepsilon$-PL hydrogels are shown in Figure 3. In general, high $\mathrm{pH}$ increased the swelling capacity of the hydrogel in ion solutions. However, the swelling degree was low at lower $\mathrm{pH}$ and the swelling degree was at a minimum at $\mathrm{pH} 2.0$. The swelling degree in $\mathrm{NaCl}$ and $\mathrm{CaCl}_{2}$ solutions were suddenly decreased at $\mathrm{pH} 5.0$. This phenomenon was attributed to the principle that the $-\mathrm{NH}^{3+}$ and $-\mathrm{COO}^{-}$groups within the network of $\gamma$-PGA/ $\varepsilon$-PL hydrogels were protonated at a lower $\mathrm{pH}$ and led to a $\mathrm{pH}$-sensitivity. The metal ions had to compete with the protons for absorbency and protonated functional groups hindered the interaction between the $\gamma$-PGA $/ \varepsilon$-PL hydrogels and metal cations [36]. Obvious metal hydroxide precipitate occurred when the $\mathrm{pH}$ increased to 6.0 for $\mathrm{Cr}^{3+}$. Hence, the optimal $\mathrm{pH}$ for $\mathrm{Cr}^{3+}$ adsorption was 5.0.

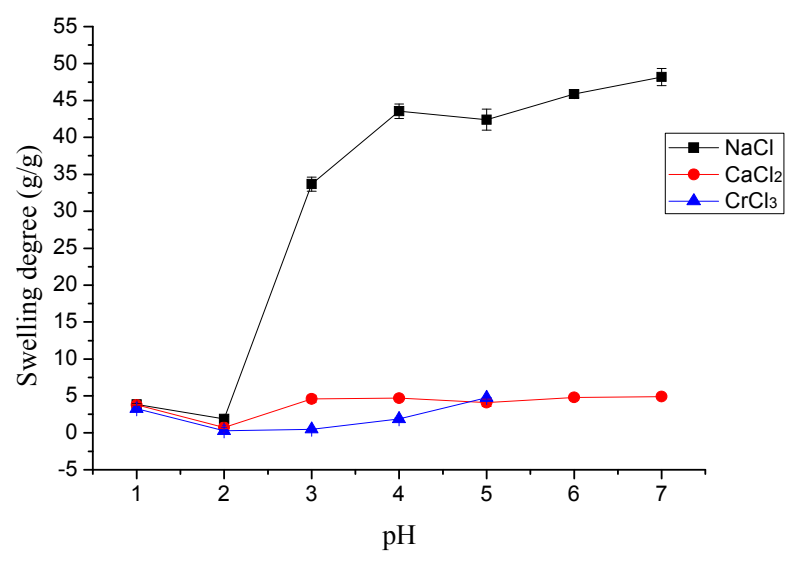

Figure 3. The effect of $\mathrm{pH}$ on the swelling study of metal ions.

Figure 4 describes the effect of temperature (pH 6.0) on the swelling behavior of $\gamma$-PGA $/ \varepsilon-\mathrm{PL}$ hydrogels. In general, the swelling degree of $\gamma$-PGA $/ \varepsilon$-PL hydrogels in $\mathrm{NaCl}$ solution was slightly raised with the temperature increasing from 15 to $60{ }^{\circ} \mathrm{C}$. However, in $\mathrm{CaCl}_{2}$ and $\mathrm{CrCl}_{3}$ solutions, the swelling degree of $\gamma$-PGA $/ \varepsilon$-PL hydrogels were slightly lower with the increase of temperature. This phenomenon was attributed to the effect of temperature and ion shielding effect. The influence of the ion shielding effect on the swelling degree was greater than that of the temperature in $\mathrm{CaCl}_{2}$ and $\mathrm{CrCl}_{3}$ solutions. In fact, the results showed that swelling behavior of $\gamma$-PGA/ $\varepsilon$-PL hydrogels in ion solutions was barely influenced by the temperature. Compared to poly( $N$-hydroxyethylacrylamide) hydrogels, $\gamma$-PGA / $\varepsilon$-PL hydrogels presented a similar phenomenon in $\mathrm{NaCl}$ solution, but the opposite phenomenon in $\mathrm{CaCl}_{2}$ and $\mathrm{CrCl}_{3}$ solutions [36].

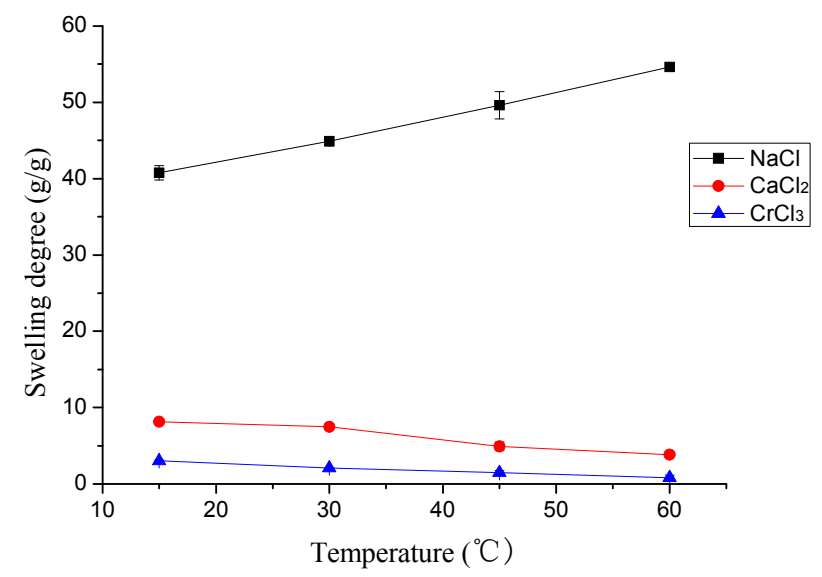

Figure 4. The effect of temperature on the swelling study of metal ions. 


\subsubsection{The Swelling Kinetic Study}

\subsubsection{The Effect of Ion Valence Number}

As presented in Figure 5, the swelling kinetic of $\gamma$-PGA / $\varepsilon$-PL hydrogels in $\mathrm{NaCl}, \mathrm{CaCl}_{2}$, and $\mathrm{CrCl}_{3}$ solutions were different. At the beginning, the swelling degree increased rapidly. At approximately $120 \mathrm{~min}$, the elevation of swelling degree was slow in both $\mathrm{NaCl}$ and $\mathrm{CaCl}_{2}$ solutions, and it decreased slightly in $\mathrm{CrCl}_{3}$ solution. In the final stage, the swelling degrees remained steady in various solutions. Finally, the swelling degrees of $\gamma$-PGA $/ \varepsilon$-PL hydrogels in $\mathrm{NaCl}, \mathrm{CaCl}_{2}$, and $\mathrm{CrCl}_{3}$ solutions were 54.91, 9.94 , and $4.86 \mathrm{~g} / \mathrm{g}$, respectively.

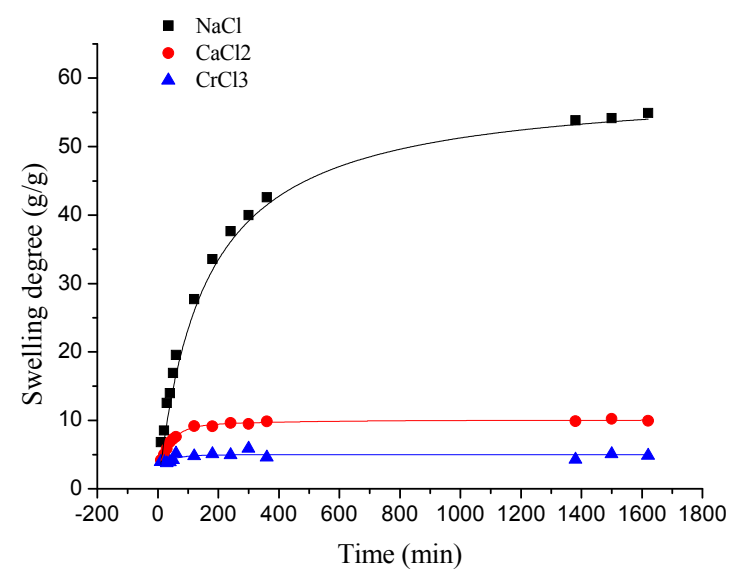

Figure 5. The swelling kinetics of $\gamma$-PGA $/ \varepsilon$-PL hydrogels in $\mathrm{NaCl}, \mathrm{CaCl}_{2}$, and $\mathrm{CrCl}_{3}$ solutions.

Compared to the swelling in ion solution of poly (aspartic acid) hydrogels, the swelling of $\gamma$-PGA/ $\varepsilon$-PL hydrogels also showed the same trend [37]. This phenomenon was due to the chemical structure of $\gamma$-PGA $/ \varepsilon$-PL hydrogels that contained a vast amount of $-\mathrm{COOH}$ and $-\mathrm{NH}_{2}$ in the polymeric network [14]. Those dissociative groups produced mutual adsorption with ions, leading to mutually exclusivity of the $-\mathrm{COO}^{-}$, and the swelling degree was restricted. As a result, $\gamma-\mathrm{PGA} / \varepsilon-\mathrm{PL}$ hydrogels were more ion-sensitive and showed more limited swelling kinetics in ion solutions with higher ionic valence numbers, as shown in Figure 6.

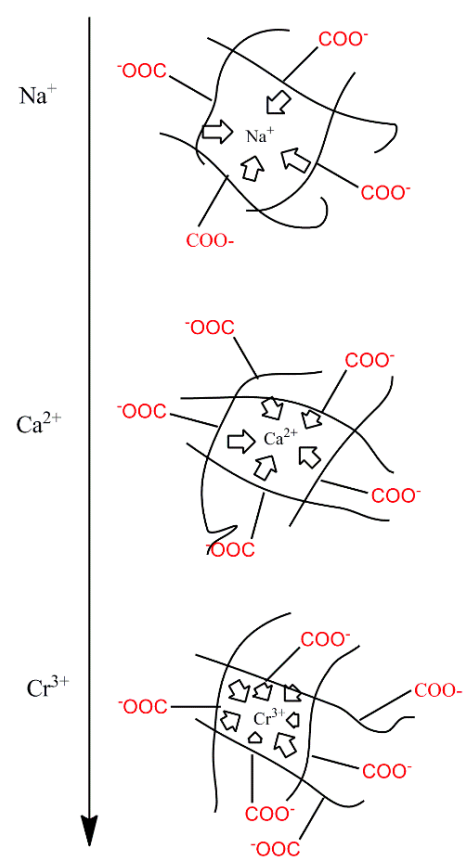

Figure 6. A schematic diagram of ionic charge shielding effect. 


\subsubsection{The Effect of $\mathrm{NaCl}$ Concentration}

In order to investigate the effect of $\mathrm{NaCl}$ concentration on the swelling kinetic of $\gamma$-PGA/ $\varepsilon$-PL hydrogels, the swelling degrees of the hydrogels were measured within the scheduled time and the swelling kinetics were fitted with adsorption kinetic models. Among numerous established adsorption kinetic models, the pseudo-first-order and pseudo-second-order kinetic models were the widely used and appropriated for study the swelling kinetic in ion solutions, such as $\mathrm{Na}(\mathrm{I}), \mathrm{Ca}(\mathrm{II}), \mathrm{Cu}(\mathrm{II})$, and $\mathrm{Cr}(\mathrm{IV})$ ion solutions $[34,38,39]$.

Figure 7 describes the plots for the pseudo-first-order and pseudo-second-order kinetics of $\gamma$-PGA / $\varepsilon$-PL hydrogels in $\mathrm{N}_{1}, \mathrm{~N}_{2}$, and $\mathrm{N}_{3}\left(\mathrm{~N}_{1}: 0.0154 \mathrm{~mol} / \mathrm{L}, \mathrm{N}_{2}: 0.0308 \mathrm{~mol} / \mathrm{L}, \mathrm{N}_{3}: 0.154 \mathrm{~mol} / \mathrm{L}\right)$. Table 2 lists the kinetic parameters of the pseudo-first-order and pseudo-second-order models. From Table 2, it can be seen that the linearly dependent coefficient $\left(R_{\mathrm{adj}}{ }^{2}\right)$ for the pseudo-first-order model was very high. However, there were great differences between the experimental swelling degree $\left(Q_{e, e}\right)$ and the calculated swelling degree $\left(Q_{e, c}\right)$, which indicates that the pseudo-first-order model was unfit for the adsorption processes of $\gamma$-PGA $/ \varepsilon$-PL hydrogels. However, the pseudo-second-order model revealed relatively higher linearly-dependent coefficients, which were all over 0.99 . Moreover, the value of the experimental swelling degree $\left(Q_{e, e}\right)$ w closer to the calculated swelling degree $\left(Q_{e, c}\right)$. These showed that the adsorption processes of $\gamma$-PGA $/ \varepsilon$-PL hydrogels and the composites for $\mathrm{Na}(\mathrm{I})$ could be perfectly expressed by the pseudo-second order model $[34,36]$.

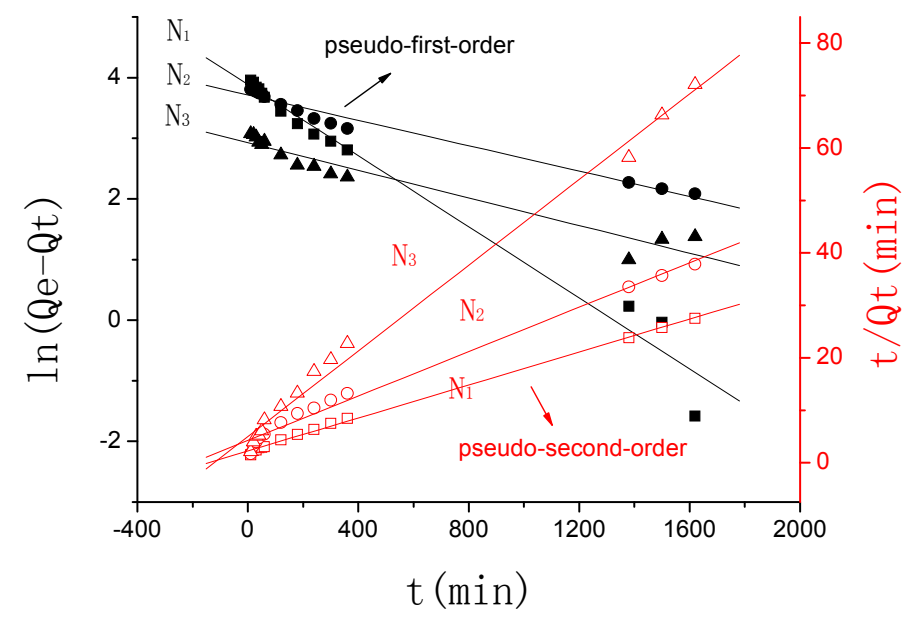

Figure 7. Pseudo-first-order and pseudo-second-order kinetic plot for the adsorption of $\gamma$-PGA/ $\varepsilon$-PL hydrogel in $\mathrm{NaCl}$ solution.

Table 2. Constants and correlation coefficients of the two kinetic models for $\mathrm{Na}(\mathrm{I})$ adsorption onto $\gamma$-PGA/ $\varepsilon$-PL hydrogels $\left(\mathrm{N}_{1}: 0.0154 \mathrm{~mol} / \mathrm{L}, \mathrm{N}_{2}: 0.0308 \mathrm{~mol} / \mathrm{L}, \mathrm{N}_{3}: 0.154 \mathrm{~mol} / \mathrm{L}\right)$.

\begin{tabular}{|c|c|c|c|c|c|c|c|}
\hline & \multirow{2}{*}{$Q_{\mathrm{e}, \mathrm{e}}(\mathrm{g} / \mathrm{g})$} & \multicolumn{3}{|c|}{ Pseudo-First-Order } & \multicolumn{3}{|c|}{ Pseudo-Second-Order } \\
\hline & & $K_{1}\left(\min ^{-1}\right)$ & $Q_{e, c}(g / g)$ & $R_{\mathrm{adj}^{2}}$ & $K_{2}\left(\min ^{-1}\right)$ & $Q_{e, c}(g / g)$ & $R_{\mathrm{adj}^{2}}$ \\
\hline $\mathrm{N}_{1}$ & 59.12 & 0.00293 & 48.68 & 0.97646 & 0.000110385 & 63.61 & 0.9983 \\
\hline $\mathrm{N}_{2}$ & 50.80 & 0.00105 & 41.01 & 0.97574 & 0.000105524 & 47.24 & 0.99106 \\
\hline $\mathrm{N}_{3}$ & 26.42 & 0.00104 & 18.66 & 0.93623 & 0.000333858 & 24.49 & 0.9931 \\
\hline
\end{tabular}

As shown in Figure 8, the swelling kinetics of $\gamma$-PGA/ $\varepsilon$-PL hydrogels in both concentrations expressed similar trends. Under the condition of the same concentration, adsorption capacities of ions increased rapidly and steadily with the increase of time (less than $800 \mathrm{~min}$ ). At higher contact times, the increase in uptake slowed. However, the adsorption capacities of ions was decreased obviously with the increased of $\mathrm{NaCl}$ concentration, which indicated that the adsorption process was high concentration dependence manner [21,40]. This phenomenon is consistent with previous 
studies [14,41]. Compared to $\gamma$-PGA or $\varepsilon$-PL hydrogels, $\gamma$-PGA $/ \varepsilon$-PL hydrogels presented good swelling capacities and a higher swelling degree in $\mathrm{NaCl}$ solution. This was due to the fact that $\gamma$-PGA $/ \varepsilon$-PL hydrogels contained a mass of bonds of -CONH-, which could obviously mitigate the charge shielding effect of ions in the hydrogel's network [14].

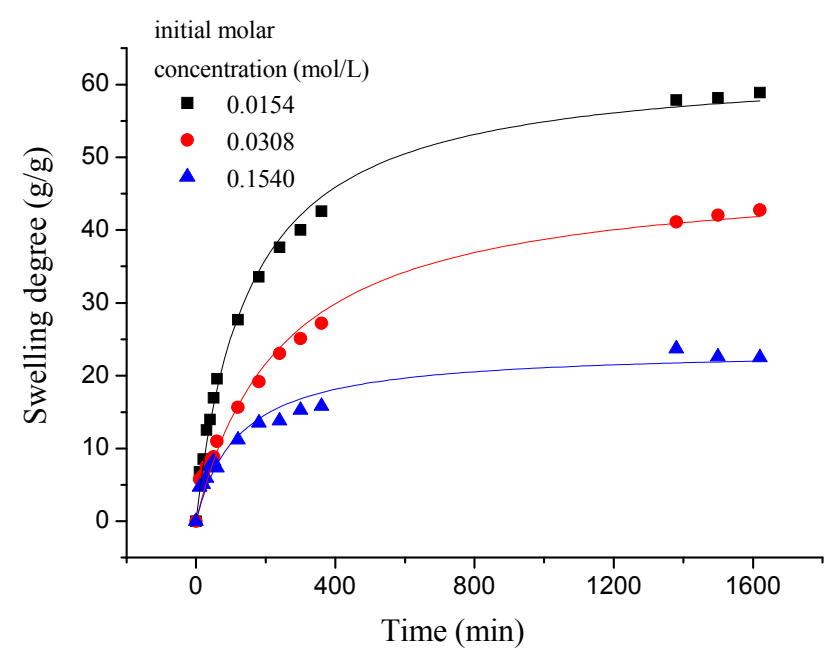

Figure 8. The swelling kinetics of $\gamma$-PGA/ $\varepsilon$-PL hydrogels in $\mathrm{NaCl}$ solution.

\subsubsection{The Effect of $\mathrm{CaCl}_{2}$ Concentration}

Similar to the adsorption kinetic in $\mathrm{NaCl}$ solution, as shown in Figure 9, the adsorption kinetics of $\gamma$-PGA/ $\varepsilon$-PL hydrogels in $\mathrm{CaCl}_{2}$ solution were also fitted typical pseudo-second order kinetics model. Figure 10 described the plots for pseudo-first-order and pseudo-second-order kinetics of $\gamma$-PGA $/ \varepsilon$-PL hydrogels in $\mathrm{N}_{1}, \mathrm{~N}_{2}$, and $\mathrm{N}_{3}\left(\mathrm{~N}_{1}: 0.0154 \mathrm{~mol} / \mathrm{L}, \mathrm{N}_{2}: 0.0308 \mathrm{~mol} / \mathrm{L}\right.$, and $\left.\mathrm{N}_{3}: 0.154 \mathrm{~mol} / \mathrm{L}\right)$. Table 3 lists the kinetic parameters of the pseudo-first-order and pseudo-second-order models. Compared with the pseudo-first-order, it shows that the pseudo-second-order model presents a relatively higher correlation coefficient $\left(R_{\mathrm{adj}}{ }^{2}>0.99\right)$, and it has a closer experimental swelling degree $\left(Q_{\mathrm{e}, \mathrm{e}}\right)$ and calculated swelling degree $\left(Q_{e, c}\right)$. This indicates that the adsorption kinetic of $\gamma$-PGA $/ \varepsilon-P L$ hydrogels in $\mathrm{CaCl}_{2}$ solution follow the pseudo-second-order model and shows that the rate-limiting step of swelling in $\mathrm{CaCl}_{2}$ solution was chemisorption and chelation involving valence forces through the sharing or exchange of electrons between the $\gamma$-PGA/ $\varepsilon$-PL hydrogels and ions [42].

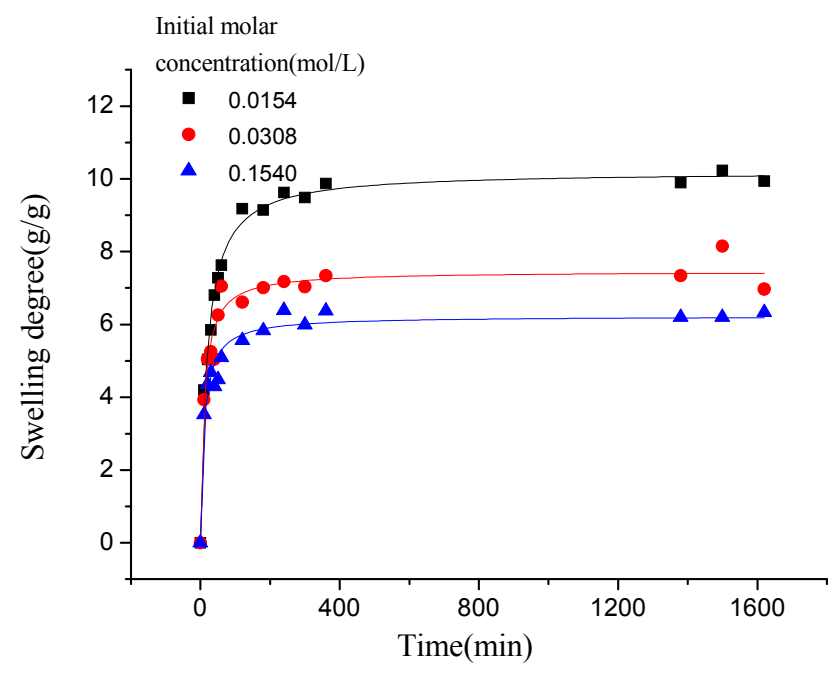

Figure 9. The swelling kinetics of $\gamma$-PGA/ $\varepsilon$-PL hydrogels in $\mathrm{CaCl}_{2}$ solution. 


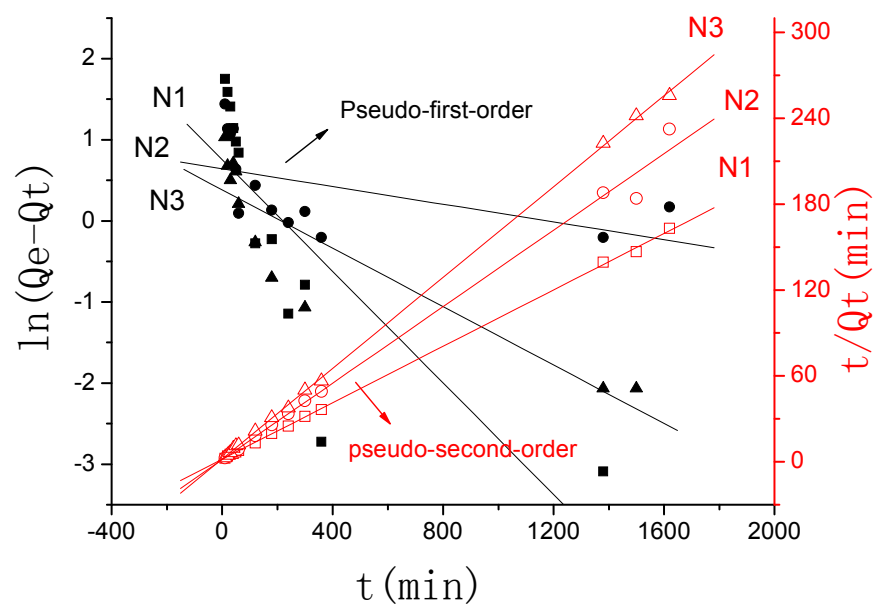

Figure 10. Pseudo-first-order and pseudo-second-order kinetic plot for the adsorption of $\gamma$-PGA/ $\varepsilon$-PL hydrogels in $\mathrm{CaCl}_{2}$ solution.

Table 3. Constants and correlation coefficients of the two kinetic models for $\mathrm{Ca}(\mathrm{II})$ adsorption onto $\gamma$-PGA/ $\varepsilon$-PL hydrogels (N1: $0.0154 \mathrm{~mol} / \mathrm{L}, \mathrm{N} 2: 0.0308 \mathrm{~mol} / \mathrm{L}, \mathrm{N} 3: 0.154 \mathrm{~mol} / \mathrm{L}$ ).

\begin{tabular}{|c|c|c|c|c|c|c|c|}
\hline & \multirow{2}{*}{$Q_{e, \mathrm{e}}(\mathrm{g} / \mathrm{g})$} & \multicolumn{3}{|c|}{ Pseudo-First-Order } & \multicolumn{3}{|c|}{ Pseudo-Second-Order } \\
\hline & & $K_{1}\left(\min ^{-1}\right)$ & $Q_{\mathrm{e}, \mathrm{c}}(\mathrm{g} / \mathrm{g})$ & $R_{\mathrm{adj}^{2}}{ }^{2}$ & $K_{2}\left(\min ^{-1}\right)$ & $Q_{\mathrm{e}, \mathrm{c}}(\mathrm{g} / \mathrm{g})$ & $R_{\mathrm{adj}^{2}}$ \\
\hline $\mathrm{N}_{1}$ & 9.94 & 0.00344 & 2.13 & 0.63707 & 0.005619146 & 10.14 & 0.99965 \\
\hline $\mathrm{N}_{2}$ & 8.15 & 0.00091 & 1.99 & 0.34821 & 0.012211097 & 7.49 & 0.99345 \\
\hline $\mathrm{N}_{3}$ & 6.33 & 0.0018 & 1.47 & 0.79817 & 0.013841741 & 6.30 & 0.99973 \\
\hline
\end{tabular}

\subsubsection{The Effect of $\mathrm{CrCl}_{3}$ Concentration}

As shown in Figure 11, compared to the swelling kinetics of $\gamma$-PGA/ $\varepsilon$-PL hydrogels in the above two kinds of ions solution, the swelling kinetics of hydrogels in $\mathrm{CrCl}_{3}$ solution showed different trends. In less than $120 \mathrm{~min}$, the swelling degree increased rapidly, compared to that observed in $\mathrm{NaCl}$ and $\mathrm{CaCl}_{2}$ solutions. However, when $\gamma$-PGA/ $\varepsilon$-PL hydrogels swelled from $120 \mathrm{~min}$ to $360 \mathrm{~min}$, the swelling degrees appeared to irregularly rise and fall. After more than $360 \mathrm{~min}$, the swelling degrees were decreased to about $1.15 \mathrm{~g} / \mathrm{g}$ because the $\mathrm{Cr}^{3+}$ has a stronger charge shielding effect than $\mathrm{Na}^{+}$and $\mathrm{Ca}^{2+}$. When the $\gamma$-PGA/ $\varepsilon$-PL hydrogel-adsorbing $\mathrm{Cr}^{3+}$ solution reached the critical point, the stronger charge attraction force between $\mathrm{Cr}^{3+}$ and $-\mathrm{COO}^{-}$maintained a balance with the total of repulsive force between $-\mathrm{COO}^{-}$and other forces. Then, the charge attraction forces between $\mathrm{Cr}^{3+}$ and $-\mathrm{COO}^{-}$became stronger because the hydrogels adsorbed more ions, which collapsed the network structure of the hydrogels [43].

\subsection{The Desorption Kinetic}

The desorption rate of $\gamma$-PGA $/ \varepsilon$-PL hydrogels in $\mathrm{NaCl}, \mathrm{CaCl}_{2}$, and $\mathrm{CrCl}_{3}$ solutions at different times is shown in Figure 12. In previous studies, the desorption process of some ions from hydrogels obeyed pseudo-first-order kinetics [35]. However, as shown in Figure 13 and Table 4, the pseudo-first-order model presented relatively lower correlation coefficients $\left(R_{\text {adj }}{ }^{2}<0.90\right)$ in $\mathrm{NaCl}$ and $\mathrm{CaCl}_{2}$ solutions, and they had different values between experimental conductivity $\left(\Lambda_{\mathrm{m}, \mathrm{m}}\right)$ and calculated conductivity $\left(\Lambda_{\mathrm{m}, \mathrm{c}}\right)$. This might due to the appearance of re-adsorption ions of hydrogels in the desorption media. Before $60 \mathrm{~min}$, desorption capacities of ions increased rapidly. However, the release rate of $\mathrm{Na}^{+}$was the highest in the whole solutions (the concentration increased from $0.01157 \mathrm{~mol} / \mathrm{L}$ to $0.01948 \mathrm{~mol} / \mathrm{L}$ ). The uptake rate decreased after that. This might also be due to the charge shielding effect of ions in the hydrogel's network. In deionized water, when the hydrogels containing adsorbed ions were subjected to water molecules, the ions on the surface of hydrogels 
readily hydrated and desorbed from the hydrogel as they weakly interacted on the surface, which was attributed to the initial rapid increase in conductivity that, later on, slows down as time proceeds. The hydration reduced the stiffness of cross-linked units with the hydrogel and that weakened the interactions between the adsorbed ions and the cross-linked units, which led to desorption of ions from the hydrogel's network.

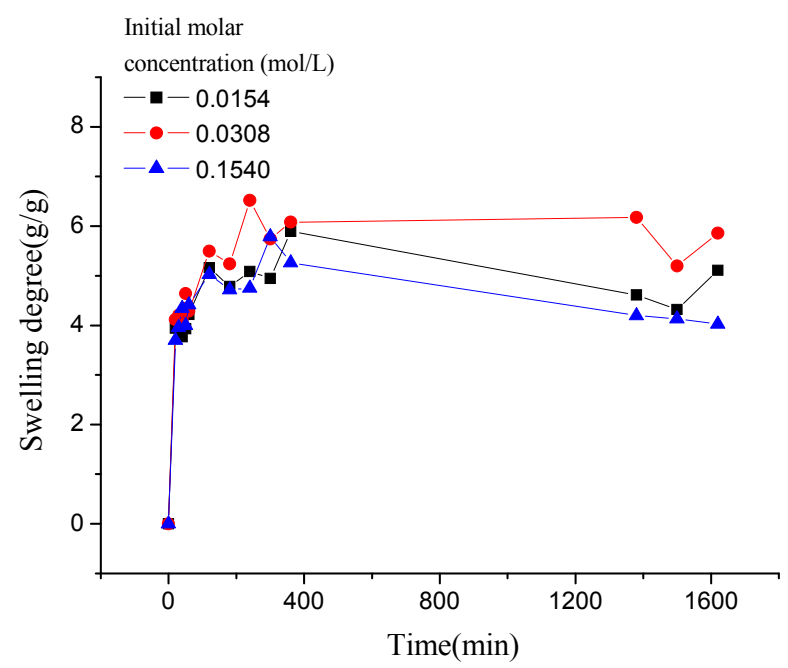

Figure 11. The swelling kinetics of $\gamma$-PGA/ $\varepsilon$-PL hydrogels in $\mathrm{CrCl}_{3}$ solution.

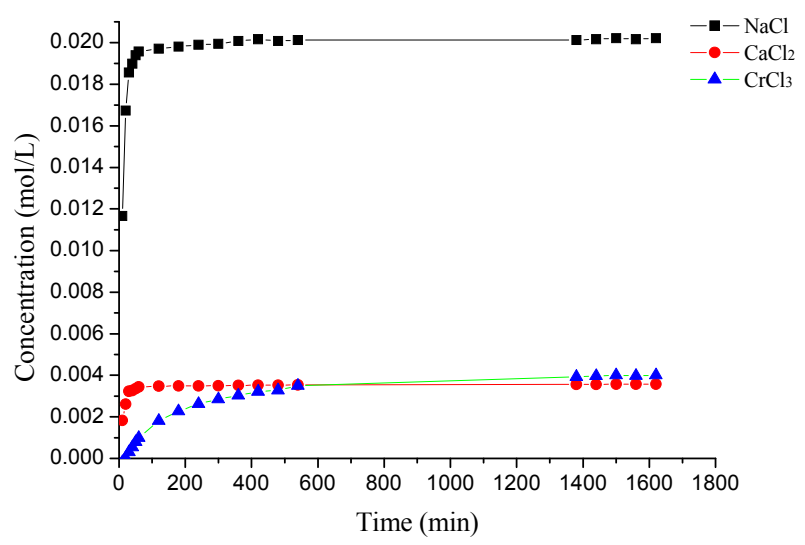

Figure 12. The desorption kinetics of $\gamma$-PGA $/ \varepsilon$-PL hydrogels in ion solutions.

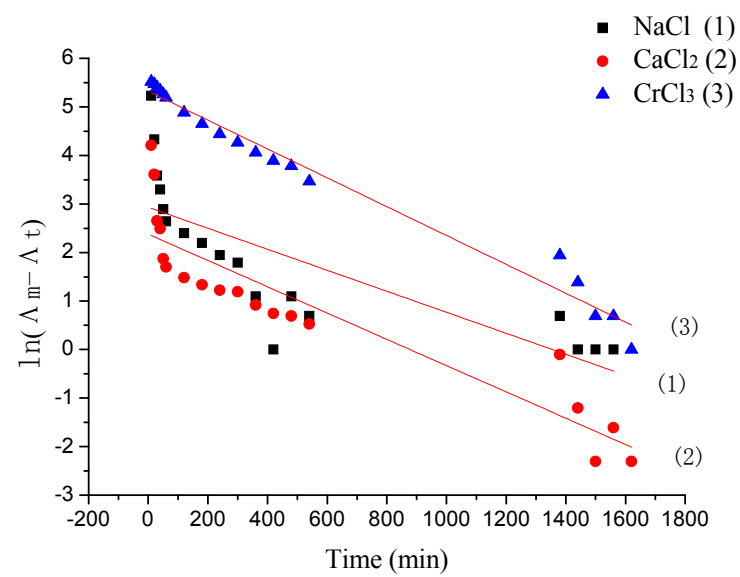

Figure 13. Pseudo-first-order kinetic plot for the desorption of $\gamma$-PGA/ $\varepsilon$-PL hydrogels in $\mathrm{NaCl}, \mathrm{CaCl}_{2}$, and $\mathrm{CrCl}_{3}$ solutions. 
Table 4. Constants and correlation coefficients of pseudo-first-order kinetic models for $\mathrm{NaCl}$ (1), $\mathrm{CaCl}_{2}$ (2), and $\mathrm{CrCl}_{3}$ (3) adsorption onto $\gamma$-PGA/ $\varepsilon$-PL hydrogels.

\begin{tabular}{ccccc}
\hline & & \multicolumn{3}{c}{ Pseudo-First-Order } \\
\cline { 3 - 5 } & $\boldsymbol{\Lambda}_{\mathbf{m}, \mathbf{m}}(\boldsymbol{\mu s})$ & $\boldsymbol{K}_{\mathbf{1}}\left(\mathbf{m i n}^{-\mathbf{1}}\right)$ & $\boldsymbol{\Lambda}_{\mathbf{m}, \mathbf{c}}(\boldsymbol{\mu s})$ & $\boldsymbol{R}_{\mathbf{a d j}}{ }^{2}$ \\
\hline$(1)$ & 2358.5 & 0.00216 & 2185.29 & 0.57959 \\
$(2)$ & 832.3 & 0.00271 & 822.59 & 0.82502 \\
$(3)$ & 1409.56 & 0.00297 & 1400.79 & 0.97701 \\
\hline
\end{tabular}

\section{Conclusion}

In this study, novel $\gamma$-PGA/ $\varepsilon$-PL hydrogels were successful prepared by the EDC/NHS mediated system. The $\mathrm{pH}$ significantly influenced the swelling capacities of $\gamma$-PGA hydrogels. The swelling capacity of $\gamma$-PGA $/ \varepsilon$-PL hydrogels decreased with the increase of the ion concentration. The swelling kinetics presented that $\gamma$-PGA $/ \varepsilon$-PL hydrogels were ion-sensitive and showed a more limited swelling degree in ion solutions with higher ionic valence numbers. The swelling degrees of $\gamma$-PGA/ $\varepsilon$-PL hydrogels in $\mathrm{NaCl}, \mathrm{CaCl}_{2}$, and $\mathrm{CrCl}_{3}$ solutions were $54.91,9.94$, and $4.86 \mathrm{~g} / \mathrm{g}$, respectively. Additionally, the swelling kinetics of $\gamma$-PGA/ $/ \varepsilon$-PL hydrogels showed that the pseudo-second order kinetic model presented relatively higher linear correlation coefficients (over 0.99 ) in $\mathrm{NaCl}$ and $\mathrm{CaCl}_{2}$ solutions. The desorption capacities of ions increased rapidly with time (before $60 \mathrm{~min}$ ) and the release rate of $\mathrm{Na}^{+}$was at its maximum in various solutions $(0.01948 \mathrm{~mol} / \mathrm{L})$.

On the whole, $\gamma$-PGA $/ \varepsilon$-PL hydrogels presented ionic sensitivity and desorption of ions. Swelling and desorption kinetics indicated that $\gamma$-PGA $/ \varepsilon-$ PL hydrogels might be used in some key applications, such as drug release, absorbents, ion-sensitive smart materials, etc.

Acknowledgments: This work was financially supported by the National Key R and D Program of China (2017YFB0309800), the National Natural Science Foundation of China (No. 31200719, 51403152, 51473122), the Natural Science Foundation of Tianjin (16JCTPJC44400, 14JCQNJC14200), and the Tianjin Municipal Special Program of Talents Development for Excellent Youth Scholars.

Author Contributions: Yu Wang and Zheng Li put forward the experimental idea; Guidong He and Jiachuan Hua designed and performed the experiments and drafted the manuscript; Maoqi Wu and Jixian Gong performed the characterization and kinetic study; Li-tong Ban and Liang Huang supervised the data analysis; Jianfei Zhang revised the manuscript.

Conflicts of Interest: The authors declare no conflict of interest.

\section{References}

1. Slaughter, B.V.; Khurshid, S.S.; Fisher, O.Z.; Khademhosseini, A.; Peppas, N.A. Hydrogels in Regenerative Medicine. Adv. Mater. 2009, 21, 3307-3329. [CrossRef] [PubMed]

2. Giri, T.K.; Thakur, A.; Alexander, A.; Ajazuddin; Badwaik, H.; Tripathi, D.K. Modified chitosan hydrogels as drug delivery and tissue engineering systems: Present status and applications. Acta Pharm. Sin. B 2012, 2, 439-449. [CrossRef]

3. Galler, K.M.; D’Souza, R.N.; Hartgerink, J.D.; Schmalz, G. Scaffolds for Dental Pulp Tissue Engineering. Adv. Dent. Res. 2011, 23, 333-339. [CrossRef] [PubMed]

4. Madhumathi, K.; Shalumon, K.T.; Rani, V.V.; Tamura, H.; Furuike, T.; Selvamurugan, N.; Nair, S.V.; Jayakumar, R. Wet chemical synthesis of chitosan hydrogel-hydroxyapatite composite membranes for tissue engineering applications. Int. J. Biol. Macromol. 2009, 45, 12-15. [CrossRef] [PubMed]

5. Lee, Y.; Chang, J.; Yang, M.; Chien, C.; Lai, W. Acceleration of wound healing in diabetic rats by layered hydrogel dressing. Carbohydr. Polym. 2012, 88, 809-819. [CrossRef]

6. Dantas, M.D.M.; Cavalcante, D.R.R.; Araújo, F.E.N.; Barretto, S.R.; Aciole, G.T.S.; Pinheiro, A.L.B.; Ribeiro, M.A.G.; Lima-Verde, I.B.; Melo, C.M.; Cardoso, J.C.; et al. Improvement of dermal burn healing by combining sodium alginate/chitosan-based films and low level laser therapy. J. Photochem. Photobiol. B 2011, 105, 51-59. [CrossRef] [PubMed] 
7. Zhang, X.; Jo Lewis, P.; Chu, C. Fabrication and characterization of a smart drug delivery system: microsphere in hydrogel. Biomaterials 2005, 26, 3299-3309. [CrossRef] [PubMed]

8. Wu, J.; Wei, W.; Wang, L.; Su, Z.; Ma, G. A thermosensitive hydrogel based on quaternized chitosan and poly(ethylene glycol) for nasal drug delivery system. Biomaterials 2007, 28, 2220-2232. [CrossRef] [PubMed]

9. Paulino, A.T.; Guilherme, M.R.; Reis, A.V.; Campese, G.M.; Muniz, E.C.; Nozaki, J. Removal of methylene blue dye from an aqueous media using superabsorbent hydrogel supported on modified polysaccharide. J. Colloid Interface Sci. 2006, 301, 55-62. [CrossRef] [PubMed]

10. Bao, Y.; Ma, J.; B, N. L. Synthesis and swelling behaviors of sodium carboxymethyl cellulose- $g$-poly (AA-co-AM-co-AMPS)/MMT superabsorbent hydrogel. Carbohydr. Polym. 2011, 84, 76-82. [CrossRef]

11. Garcia, J.P.D.; Hsieh, M.; Bonifacio Tobias Doma, J.; Peruelo, D.C.; Chen, I.; Lee, H. Synthesis of Gelatin- $\gamma$-Polyglutamic Acid- Based Hydrogel for the In Vitro Controlled Release of Epigallocatechin Gallate (EGCG) from Camellia sinensis. Polymers 2014, 6, 39-58. [CrossRef]

12. Baier Leach, J.; Bivens, K.A.; Patrick, C.W.J.; Schmidt, C.E. Photocrosslinked hyaluronic acid hydrogels: Natural, biodegradable tissue engineering scaffolds. Biotechnol. Bioeng. 2003, 82, 578-589. [CrossRef] [PubMed]

13. Ji, D.Y.; Kuo, T.F.; Wu, H.D.; Yang, J.C.; Lee, S.Y. A novel injectable chitosan/polyglutamate polyelectrolyte complex hydrogel with hydroxyapatite for soft-tissue augmentation. Carbohydr. Polym. 2012, 89, 1123-1130. [CrossRef] [PubMed]

14. Hua, J.; Li, Z.; Xia, W.; Yang, N.; Gong, J.; Zhang, J.; Qiao, C. Preparation and properties of EDC/NHS mediated crosslinking poly(gamma-glutamic acid)/epsilon-polylysine hydrogels. Mat. Sci. Eng. C 2016, 61, 879-892. [CrossRef] [PubMed]

15. Zhang, S.; Zhou, Y.; Nie, W.; Song, L.; Zhang, T. Preparation of Uniform Magnetic Chitosan Microcapsules and Their Application in Adsorbing Copper Ion(II) and Chromium Ion(III). Ind. Eng. Chem. Res. 2012, 51, 14099-14106. [CrossRef]

16. Zhang, S.; Zhou, Y.F.; Nie, W.Y.; Song, L.Y. Preparation of $\mathrm{Fe}_{3} \mathrm{O}_{4}$ / chitosan/poly(acrylic acid) composite particles and its application in adsorbing copper ion(II). Cellulose 2012, 19, 2081-2091. [CrossRef]

17. Ngah, W.S.W.; Hanafiah, M.A.K.M. Removal of heavy metal ions from wastewater by chemically modified plant wastes as adsorbents: A review. Bioresour. Technol. 2008, 99, 3935-3948. [CrossRef] [PubMed]

18. O'Connell, D.W.; Birkinshaw, C.; O'Dwyer, T.F. Heavy metal adsorbents prepared from the modification of cellulose: A review. Bioresour. Technol. 2008, 99, 6709-6724. [CrossRef] [PubMed]

19. Linghu, W.S.; Wang, C. Adsorption of Heavy Metal Ions from Aqueous Solution by Chitosan. Adv. Mat. Res. 2014, 881-883, 570-573. [CrossRef]

20. Ahluwalia, S.S.; Goyal, D. Removal of Heavy Metals by Waste Tea Leaves from Aqueous Solution. Eng. Life Sci. 2005, 5, 158-162. [CrossRef]

21. Peng, X.; Zhong, L.; Ren, J.; Sun, R. Highly Effective Adsorption of Heavy Metal Ions from Aqueous Solutions by Macroporous Xylan-Rich Hemicelluloses-Based Hydrogel. J. Agric. Food Chem. 2012, 60, 3909-3916. [CrossRef] [PubMed]

22. Ozay, O.; Ekici, S.; Baran, Y.; Aktas, N.; Sahiner, N. Removal of toxic metal ions with magnetic hydrogels. Water Res. 2009, 43, 4403-4411. [CrossRef] [PubMed]

23. Yan, J.J.; Li, Z.; Zhang, J.F.; Qiao, C.S. Preparation and Properties of Pullulan Composite Films. Adv. Mat. Res. 2012, 476-478, 2100-2104. [CrossRef]

24. Seliktar, D. Designing cell-compatible hydrogels for biomedical applications. Science 2012, 336, $1124-1128$. [CrossRef] [PubMed]

25. Pooley, S.A.; Rivas, B.L.; Carcamo, A.L.; Del, C.; Pizarro, G. Hydrogels from $N, N^{\prime}$-dimethylacrylamide-co2-acrylamido-2-methyl-1-propanesulfonic acid with salt-, temperature- and $\mathrm{pH}$-responsiveness properties. J. Chil. Chem. Soc. 2008, 53, 1483-1489. [CrossRef]

26. Tang, D.; Yu, S.; Ho, Y.; Huang, B.; Tsai, G.; Hsieh, H.; Sung, H.; Mi, F. Characterization of tea catechins-loaded nanoparticles prepared from chitosan and an edible polypeptide. Food Hydrocoll. 2013, 30, 33-41. [CrossRef]

27. Shih, I.; Van, Y. The production of poly-( $\gamma$-glutamic acid $)$ from microorganisms and its various applications. Bioresour. Technol. 2001, 79, 207-225. [CrossRef]

28. Yoshida, T.; Nagasawa, T. $\varepsilon$-Poly-L-lysine: Microbial production, biodegradation and application potential. Appl. Microbiol. Biotechnol. 2003, 62, 21-26. [CrossRef] [PubMed] 
29. El-Sersy, N.A.; Abdelwahab, A.E.; Abouelkhiir, S.S.; Abou-Zeid, D.M.; Sabry, S.A. Antibacterial and Anticancer activity of $\varepsilon$-poly-L-lysine ( $\varepsilon$-PL) produced by a marine Bacillus subtilis sp. J. Basic Microbiol. 2012, 52, 513-522. [CrossRef] [PubMed]

30. Ye, R.; Xu, H.; Wan, C.; Peng, S.; Wang, L.; Xu, H.; Aguilar, Z.P.; Xiong, Y.; Zeng, Z.; Wei, H. Antibacterial activity and mechanism of action of $\varepsilon$-poly-L-lysine. Biochem. Biophys. Res. Commun. 2013, 439, 148-153. [CrossRef] [PubMed]

31. Maitra, J.; Singh, N. Swelling behavior of starch chitosan polymeric blend. Adv. Polym. Sci. Technol. Int. J. 2014, 4, 22-27.

32. Kunioka, M.; Choi, H.J. Preparation conditions and swelling equilibria of biodegradable hydrogels prepared from microbial poly( $\gamma$-glutamic acid) and poly( $\varepsilon$-lysine). J. Polym. Environ. 1996, 4, 123-129. [CrossRef]

33. Ho, Y.S.; McKay, G. Pseudo-second order model for sorption processes. Process Biochem. 1999, 34, 451-465. [CrossRef]

34. Wang, X.; Zheng, Y.; Wang, A. Fast removal of copper ions from aqueous solution by chitosan-g-poly(acrylic acid)/attapulgite composites. J. Hazard. Mater. 2009, 168, 970-977. [CrossRef] [PubMed]

35. Saeed, R.; Ul Abdeen, Z. Kinetics of desorption of KCL from polyvinyl alcohol-borate hydrogel in aqueous-alcoholic solvents at different temperatures. Russ. J. Phys. Chem. A 2015, 89, 2126-2131. [CrossRef]

36. Hua, R.; Li, Z. Sulfhydryl functionalized hydrogel with magnetism: Synthesis, characterization, and adsorption behavior study for heavy metal removal. Chem. Eng. J. 2014, 249, 189-200. [CrossRef]

37. Zhao, Y.; Su, H.; Fang, L.; Tan, T. Superabsorbent hydrogels from poly(aspartic acid) with salt-, temperatureand $\mathrm{pH}$-responsiveness properties. Polymer 2005, 46, 5368-5376. [CrossRef]

38. Mittal, H.; Maity, A.; Ray, S.S. Synthesis of co-polymer-grafted gum karaya and silica hybrid organic-inorganic hydrogel nanocomposite for the highly effective removal of methylene blue. Chem. Eng. J. 2015, 279, 166-179. [CrossRef]

39. Kim, M.K.; Shanmuga Sundaram, K.; Anantha Iyengar, G.; Lee, K. A novel chitosan functional gel included with multiwall carbon nanotube and substituted polyaniline as adsorbent for efficient removal of chromium ion. Chem. Eng. J. 2015, 267, 51-64. [CrossRef]

40. Zhu, B.; Fan, T.; Zhang, D. Adsorption of copper ions from aqueous solution by citric acid modified soybean straw. J. Hazard. Mater. 2008, 153, 300-308. [CrossRef] [PubMed]

41. Omidian, H.; Hashemi, S.A.; Sammes, P.G.; Meldrum, I. A model for the swelling of superabsorbent polymers. Polymer 1998, 39, 6697-6704. [CrossRef]

42. Gupta, V.K.; Rastogi, A. Biosorption of lead from aqueous solutions by green algae Spirogyra species: Kinetics and equilibrium studies. J. Hazard. Mater. 2008, 152, 407-414. [CrossRef] [PubMed]

43. Li, Z.; He, G.; Hua, J.; Wu, M.; Guo, W.; Gong, J.; Zhang, J.; Qiao, C. Preparation of $\gamma$-PGA hydrogels and swelling behaviors in salt solutions with different ionic valence numbers. RSC Adv. 2017, 7, 11085-11093. [CrossRef]

(C) 2018 by the authors. Licensee MDPI, Basel, Switzerland. This article is an open access article distributed under the terms and conditions of the Creative Commons Attribution (CC BY) license (http://creativecommons.org/licenses/by/4.0/). 